\title{
Use of Shearing Operation for MS Bar Cutting by Pneumatic Bar Cutting Machine
}

\author{
Dayanand A. Ghatge ${ }^{1}$, Charudatta Birje ${ }^{2}$, Priyanka S. Yadav ${ }^{3}$ \\ Dept of Mechanical Engineering, Karmaveer Bhaurao Patil College of Engineering, Satara, Maharashtra, India ${ }^{1,2,3}$
}

\begin{abstract}
The bar cutting machine is used to cut mild steel bar by using shearing operation. Shearing operation uses punch and die. A punch (or moving blade) is used to push the work piece against the die (or fixed blade), which is fixed. Usually the clearance between the two is 5 to $10 \%$ of the thickness of the material, but dependent on the material. Clearance is defined as the separation between the blades, measured at the point where the cutting action takes place and perpendicular to the direction of blade movement. This causes the material to experience highly localized shear stresses between the punch and die. The material will then fail when the punch has moved 15 to $60 \%$ the thickness of the material, because the shear stresses are greater than the shear strength of the material and the remainder of the material is torn. Two distinct sections can be seen on a sheared work piece, the first part being plastic deformation and the second being fractured. Because of normal in homogeneities in materials and inconsistencies in clearance between the punch and die, the shearing action does not occur in a uniform manner. The fracture will begin at the weakest point and progress to the next weakest point until the entire work piece has been sheared.
\end{abstract}

Keywords: Shearing operation, punch, die, cutting edge, pneumatic equipments.

\section{INTRODUCTION}

Shearing, also known as die cutting, is a process which moving blade) is used to push the work piece against the cuts stock without the formation of chips or the use of die (or fixed blade), which is fixed.

burning or melting. Strictly speaking, if the cutting blades are straight the process is called shearing; if the cutting blades are curved then they are shearing-type operations. When the stress reaches beyond the ultimate strength of the material, the fracture starts from both the sides of plate along the cutting edges of both die and the illustrated a complete shearing operation. The most commonly sheared materials are punch, and as the punch continuous to descend; the fractures meet at the centre of plate. The metal is now completely severed from the sheet metal and drops out through the die opening. The fig. 1

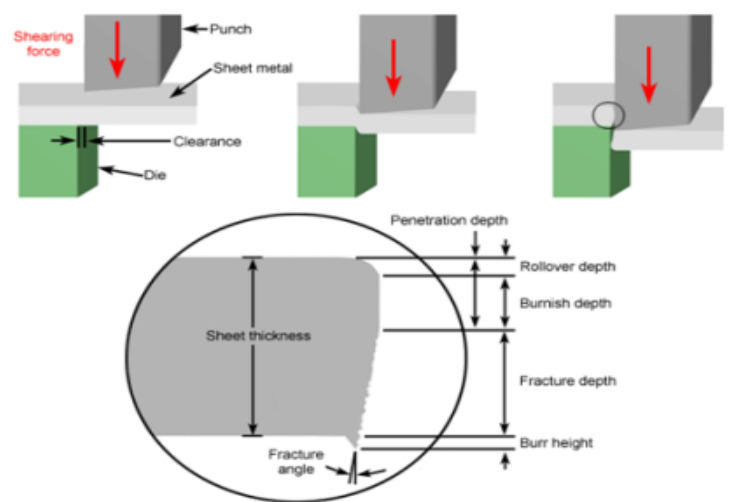

Fig.1 Principle of shear cutting

in the form of sheet metal or Plates; however rods can also be sheared. Shearing-type operations include: blanking, piercing, roll slitting, and trimming. It is used in metal working and also with paper and plastics. A punch (or

\section{MATERIALS USED FOR THE PUNCH AND DIE}

\section{A. $\mathrm{HCHCr}-$}

$\mathrm{HCHCr}$ Material also known as High Carbon High Chromium Steel or simply as D2, it is created by vacuum process. This is developed by raising the steel temperature to a high degree and then letting it cool suddenly. Due to its immovability during processing, very thin parts are also manufactured. In spite of not being classified as stainless steel, this has many properties similar to stainless steel like the following:

- Economic, Good Hardness High wear resistance

- Stainless steel properties

- Thin manufactured parts

- High abrasive wear applications

- Edge holding properties

- Accurate dimensions

Thread rolling dies, Hobs, Cold extrusion tools and dies, Punches, Draw plates and dies, Cutters, Measuring tools, Pressure casting moulds, Blanking, Reamer, Finishing rolls for tyre mills. This type of steel has high dimensional stability with added wear resistance coupled with excellent edge holding qualities.

TABLE I Typical analysis of ( $\mathrm{HCHCr})$ in \%

\begin{tabular}{ll}
\hline Steel Type & $\begin{array}{l}\text { High Carbon } \\
\text { High Chromium Die steel }\end{array}$ \\
\hline Quality & HCHC \\
\hline
\end{tabular}


Vol. 4, Special Issue 1, January 2017

\begin{tabular}{ll}
\hline AISI & D2 \\
$\mathbf{C}$ & 1.7 \\
$\mathbf{S i}$ & 0.3 \\
$\mathbf{M n}$ & 0.3 \\
$\mathbf{C r}$ & 12 \\
$\mathbf{W}$ & 0.5 \\
$\mathbf{V}$ & 0.1 \\
Mo & 0.6 \\
\hline Hardness & $58 \sim 65 \mathrm{Rc}$ \\
\hline
\end{tabular}

\section{B. MILD STEEL-}

This is made using the hot roll process. Cooled in open air, it gets a blue-black oxidized colour. In addition, cooling can be done in other ways in order to give slightly different qualities to the steel.

- High tensile strength

- Resistance to corrosion

- Cheaper prices

- High Ductility

The plain steels are generally classified in following 3 types:

1. LOW CARBON STEEL: -

It consists of up to $0.30 \%$ of carbon. Mild steel is the most common form of steel as its price is relatively low while it provides material properties that are acceptable for many applications. Low carbon steel contains approximately $0.05-0.15 \%$ carbon and mild steel contains $0.16-0.30 \%$ carbon. It is used where ductility or softness are important. Properties: Malleable and ductile, and therefore bends fairly easily

\section{MEDIUM CARBON STEEL: -}

From 0.30 to $0.60 \%$ of carbon. These are less ductile but harder and have greater tensile strength than low carbon steel. It balances ductility and strength and has good wear resistance. They have also better machining qualities.

Properties: Harder, better tensile strength, good wear resistance.

\section{HIGH CARBON STEEL: -}

From 0.60 to $1.70 \%$ of carbon. Used for special purposes like (non-industrial-purpose) knives, axles or punches. Most of these steels with more than $1.2 \%$ carbon content are made using powder metallurgy.

Properties: Tough rather than hard, and fairly ductile.

TABLE II Plain Carbon Steel Properties

\begin{tabular}{llll} 
Material & $\begin{array}{l}\text { Low } \\
\text { Carbon } \\
\text { Steel }\end{array}$ & $\begin{array}{l}\text { Medium } \\
\text { Carbon } \\
\text { Steel 0.3 } \\
\text { to 0.6\% C }\end{array}$ & $\begin{array}{l}\text { High } \\
\text { Carbon } \\
\text { Steel 0.6 to } \\
\mathbf{1 . 7 \%} \text { C }\end{array}$ \\
\hline Density & 7.86 & 7.85 & 7.84 \\
Thermal & 50 & 48 & 46 \\
Conductivity & & & \\
\hline
\end{tabular}

\begin{tabular}{lccc}
$\begin{array}{l}\text { Thermal } \\
\text { Expansion }\end{array}$ & 11.7 & 11.3 & 10.8 \\
$\begin{array}{l}\text { Young's } \\
\text { Modulus }\end{array}$ & 210 & 210 & 210 \\
$\begin{array}{l}\text { Tensile } \\
\text { Strength }\end{array}$ & 350 & 600 & 800 \\
\hline
\end{tabular}

\section{SELECTION OF PNEUMATIC EQUIPMENTS}

\section{A. Compressor Selection}

These units use piston and cylinder arrangement for compressing the air. Single stage compressors are suitable for discharge pressure up to 20 bars. In single stage compressor entire compression of air takes place in single step i.e. single stroke of piston.

TABLE III Technical Specification of Compressor

\begin{tabular}{|c|c|c|c|c|c|}
\hline Model & Power & Speed & $\begin{array}{c}\text { Free } \\
\text { air } \\
\text { disp. } \\
\text { Per } \\
\text { min }\end{array}$ & $\begin{array}{l}\text { Working } \\
\text { pressure }\end{array}$ & $\begin{array}{c}\text { Tank } \\
\text { capacity }\end{array}$ \\
\hline & (HP) & (RPM) & (litre) & $\left(\mathrm{kg} / \mathrm{cm}^{\wedge} 2\right)$ & (litre) \\
\hline TC9 & 1 & 650 & 136 & 7 & 65 \\
\hline SPTC9 & 1 & 650 & 136 & 7 & 100 \\
\hline D12 & 2 & 650 & 226 & 10 & 115 \\
\hline SPD12 & 2 & 750 & 260 & 10 & 150 \\
\hline D15 & 3 & 750 & 340 & 15 & 150 \\
\hline SPD15 & 3 & 750 & 340 & 20 & 210 \\
\hline
\end{tabular}

From table III we have selected SPD 15 air compressor Model: SPD-115

Displacement: 11.8 CFM

RPM: 750

Oil type: SAE 40

Electric motor of compressor:

3 phase induction motor with frequency $50 \mathrm{~Hz}$

I.P:55

Current: $4.5 *$ SATAR A

Voltage: $415 \mathrm{~V}$

Power: $202 \mathrm{kw} / \mathrm{HP}$

RPM: 1440

Efficiency: $82 \%$ (F.L.)

B. Pneumatic Cylinder Selection

An air cylinder is an operative device in which the state input energy of compressed air i.e. pneumatic power is converted in to mechanical output power, by reducing the pressure of the air to that of the atmosphere. Pneumatic cylinders (sometimes known as air cylinders) are mechanical devices which use the power of compressed gas to produce a force in a reciprocating linear motion.

Like hydraulic cylinders, pneumatic cylinders use the stored potential energy of a fluid, in this case compressed air, and convert it into kinetic energy as the air expands in 
an attempt to reach atmospheric pressure. This air expansion forces a piston to move in the desired direction. The piston is a disc or cylinder, and the piston rod transfers the force it develops to the object to be moved. Engineers prefer to use pneumatics sometime because they are quieter, cleaner, and do not require large amounts or space for fluid storage.

TABLE IV Specification of cylinder

\begin{tabular}{|c|c|}
\hline Fluid & Air \\
\hline Action & Double acting \\
\hline Proof pressure & $1.5 \mathrm{MPa}$ \\
\hline Maximum operating pressure & $1.0 \mathrm{MPa}$ \\
\hline \multirow{2}{*}{ Ambient and fluid temperature } & Without auto switch:- 10 to $70^{\circ} \mathrm{C}$ \\
\hline & With autio switch:- 10 to $60^{\circ} \mathrm{C}$ \\
\hline Minimum operating pressure & $0.05 \mathrm{MPa}$ \\
\hline Piston speed & 50 to $500 \mathrm{~mm} / \mathrm{s}^{\star}$ \\
\hline Cushion & Air cushion \\
\hline Thread tolerance & JIS class 2 \\
\hline Stroke length tolerance & 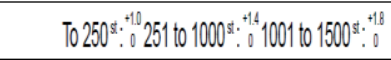 \\
\hline Lubrication & Not required (Non-lube) \\
\hline Mounting & $\begin{array}{l}\text { Basic, Foot, Front flange, Rear flange } \\
\text { Single clevis, Double clevis, Centre trunnion }\end{array}$ \\
\hline
\end{tabular}

C. Hoses Selection

TABLE V Cylinder Tube Materials

\begin{tabular}{|l|l|l|}
\hline LIGHT DUTY & $\begin{array}{l}\text { MEDIUM } \\
\text { DUTY }\end{array}$ & HEAVY DUTY \\
\hline 1. Plastic & $\begin{array}{l}\text { Hard drawn } \\
\text { brass tube }\end{array}$ & $\begin{array}{l}\text { Hard drawn brass } \\
\text { tube. }\end{array}$ \\
\hline $\begin{array}{l}\text { 2.Hard drawn } \\
\text { Aluminium } \\
\text { tube }\end{array}$ & $\begin{array}{l}\text { Aluminium } \\
\text { Castings }\end{array}$ & $\begin{array}{l}\text { Hard drawn steel } \\
\text { tube }\end{array}$ \\
\hline $\begin{array}{l}\text { 3.Hard drawn } \\
\text { Brass tube }\end{array}$ & & $\begin{array}{l}\text { Brass, Bronze, } \\
\text { Iron or Castings, } \\
\text { welded steel tube }\end{array}$ \\
\hline
\end{tabular}

D. Direction Control Valve Selection

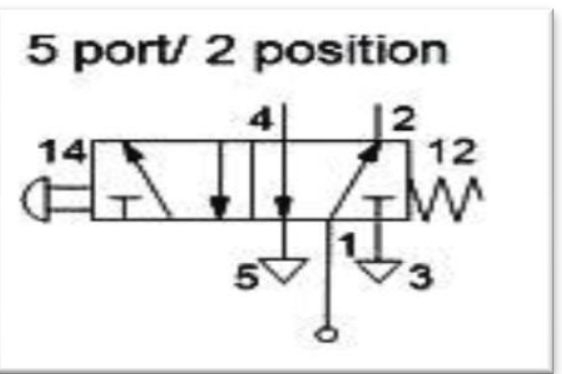

Fig.2 Symbol of 5/2 D

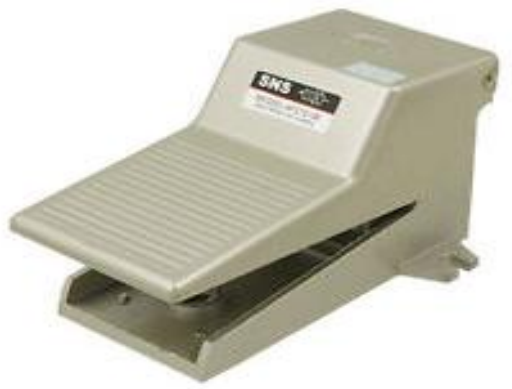

Fig. 3 Foot paddle

The directional valve is one of the important parts of a pneumatic system. Commonly known as DCV, this valve is used to control the direction of air flow in the pneumatic system. The directional valve does this by changing the position of its internal movable parts. This valve was selected for speedy operation and to reduce the manual effort and also for the modification of the machine into automatic machine by means of using a solenoid valve. A solenoid is an electrical device that converts electrical energy into straight line motion and force. These are also used to operate a mechanical operation which in turn operates the valve mechanism. Solenoids may be push type or pull type. The push type solenoid is one in which the plunger is pushed when the solenoid is energized electrically. The pull type solenoid is one is which the plunger is pulled when the solenoid is energized.

TABLE VI Piston Rod Materials

\begin{tabular}{|l|l|l|}
\hline MATERIAL & FINISH & REMARKS \\
\hline $\begin{array}{l}\text { MILD } \\
\text { STEEL }\end{array}$ & $\begin{array}{l}\text { Ground and } \\
\text { polished } \\
\text { hardened, ground } \\
\text { and polished. }\end{array}$ & $\begin{array}{l}\text { Generally } \\
\text { preferred chrome } \\
\text { plated }\end{array}$ \\
\hline $\begin{array}{l}\text { STAINLESS } \\
\text { STEEL }\end{array}$ & $\begin{array}{l}\text { Ground and } \\
\text { Polished }\end{array}$ & $\begin{array}{l}\text { Less scratch } \\
\text { resistant than } \\
\text { chrome plated } \\
\text { piston rod }\end{array}$ \\
\hline
\end{tabular}

\section{OPERATIONS}

A. Lathe Operations

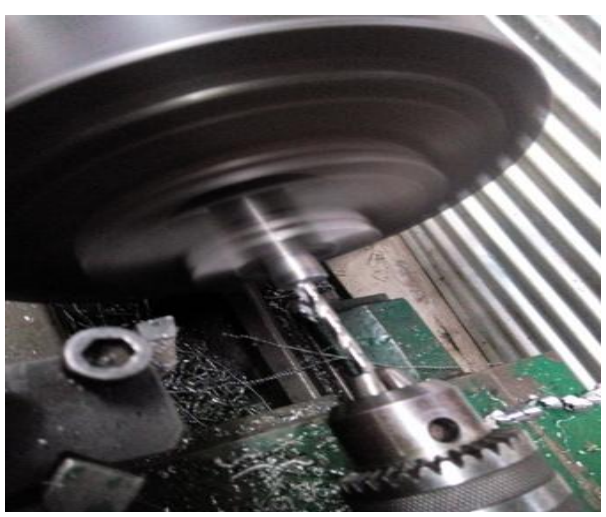

Fig .4 Lathe Operations 
IAR JSET

The lathe is one of the oldest machine tool. The main drill point is pressed at the centre point to produce function of lathe is to remove metal from the piece of required hole.

work to give the required shape and size. This is accomplished by holding the work securely and rigid on the machine and the turning it against cutting tool which will remove metal from the work in the form of chips. To cut the material properly the tool should be harder than the material of work piece, should be rigidly held on machine and should be fed or progressed in definite relative to the work.

\section{B. Planer Operations}

The planer like shaper is machine tool primarily intended to produce plane and flat surfaces by using single point cutting tool. The fundamental difference between shaper and planer is that in planer the work which is supported on the table reciprocates past the stationery cutting tool and the feed is supplied by the lateral movement of the tool. While machining horizontal surface, the work is given a reciprocating and up and down movement of table along with the tool is fed crosswise to complete the cut.

\section{Drilling Operations}

The drilling machine is one of the most important machine tool in a workshop. As regard its importance it is second only to the lathe. Although it was primarily designed to originate hole, it can perform a number of similar operations. In drilling machine holes may be drilled quickly and at low cost.

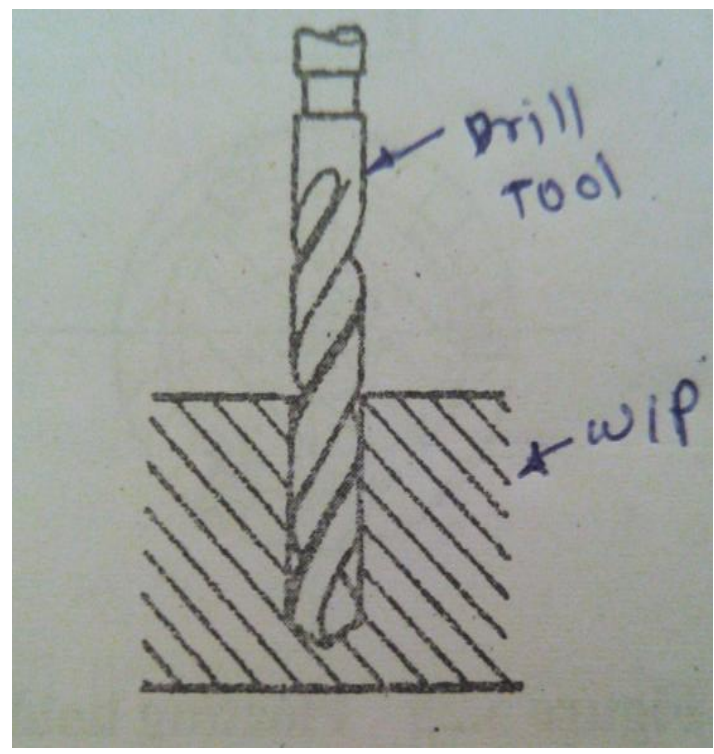

Fig. 5 Drilling Principle

The hole is generated by the rotating edge of a cutting tool known as the drill which exerts large force on the work clamped on the table. Drilling is the operation of producing cylindrical hole by removing metal by the rotating edge of cutting tool called drill. Before drilling the centre of the hole is located on the work piece by drawing two lines at right angles to each other and then centre punch is used to produce an indentation at the centre. The
TABLE VII Cutting speeds for drilling

\begin{tabular}{|l|l|}
\hline & H.S.S Drills ( M per min) \\
\hline Soft cast iron & $30-45$ \\
\hline Malleable iron & $24-27$ \\
\hline Mild steel & $24-45$ \\
\hline Stainless steel & $18-21$ \\
\hline Aluminum alloys & $60-90$ \\
\hline Brass and Bronze & $60-90$ \\
\hline Copper & $18-30$ \\
\hline
\end{tabular}

D. Tapping Operations

The operation of cutting internal threads by means of cutting tool called tap. Tap may be considered as a bolt with accurate threads cut on it. The threads act as cutting edges which are hardened and ground. When the tap is screwed into the hole it removes metal and cuts internal threads which will fit into external threads of the same size.

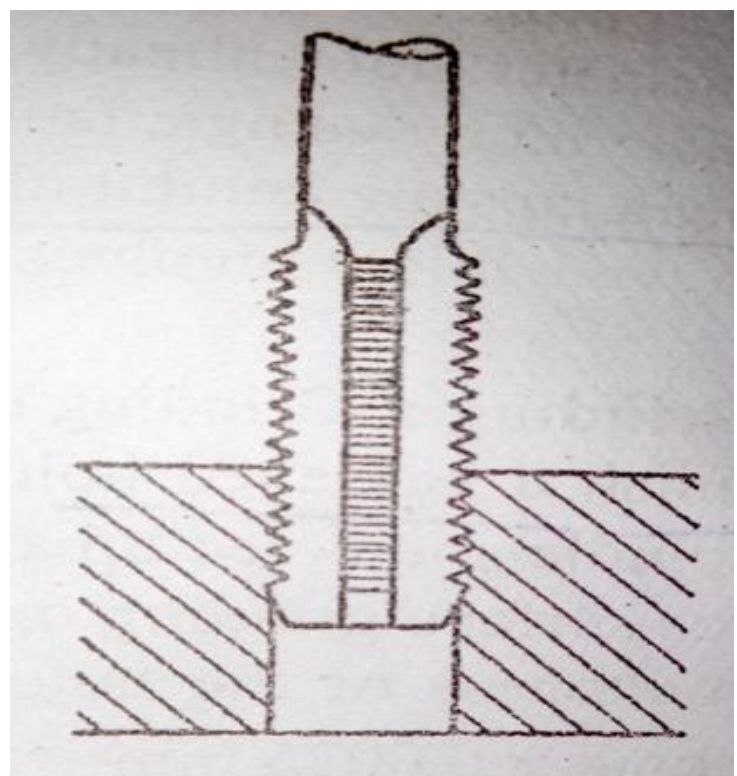

Fig. 6 Tapping Principle

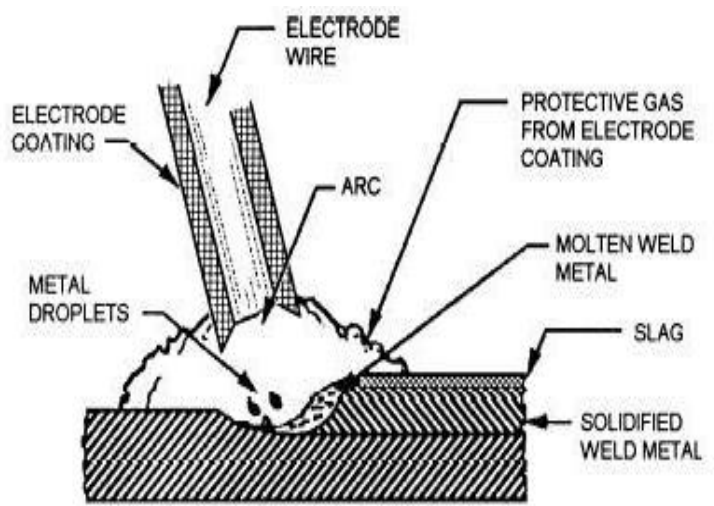

Fig. 7 Arc Welding Principle 
Vol. 4, Special Issue 1, January 2017

\section{E. Welding process}

1. Arc welding:

Arc welding is a process utilizing the concentrated heat of an electric arc to join metal by fusion of the parent metal and the addition of metal to joint usually provided by a consumable electrode. Either direct or alternating current may be used for the arc, depending upon the material to be welded and the electrode used.

A constant voltage DC power source is used. Since the spray transfer is limited to a certain range of arc current, the conventional process has a lower limit of arc current (or heat input). This also limits the application of conventional to weld material thicknesses above $4 \mathrm{~mm}$. Below $6 \mathrm{~mm}$ it is recommended that backing is used to control the weld bead.

\section{F. Grinding operations}

Grinding is metal cutting operation performed by means of rotating abrasive wheel that acts as tool. This is used to finish work pieces which must show a high surface quality, accuracy of shape and dimension. Mostly grinding is the finishing operation because it removes comparatively little metal $0.25-0.50 \mathrm{~mm}$ in most operations and accuracy in dimension is in the order of $0.000025 \mathrm{~mm}$. Grinding is also done to machine materials which are too hard for other machining methods that use cutting tools.

Cylindrical Grinder-

Cylindrical grinders are intended primarily for grinding plain cylindrical parts, although they can be used for grinding contoured cylinders, fillets and even cam and crankshafts.

Cylindrical grinding machine used to shape the outside of an object. The object must have a central axis of rotation. Cylindrical grinding is defined as having four essential actions:

1. The work (object) must be constantly rotating.

2. The grinding wheel must be constantly rotating.

3 . The grinding wheel is fed towards and away from the work.

4. Either the work or the grinding wheel is traversed with respect to other.

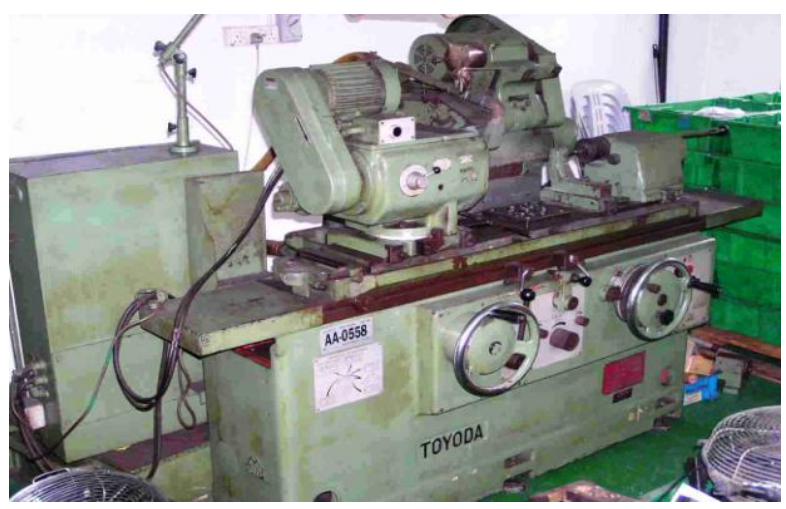

Fig 8.Cylindrical Grinder

G. Sawing and finishing operations

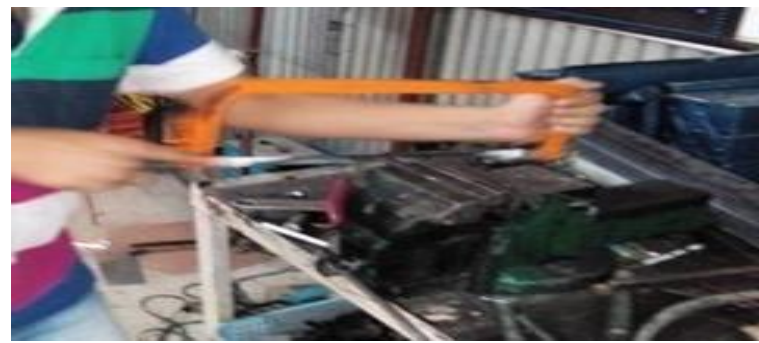

Fig. 9 Sawing operations

\section{DRAWING OF PUNCH, DIE AND PUNCH HOLDER}

\section{A. DRAWING OF PUNCH}

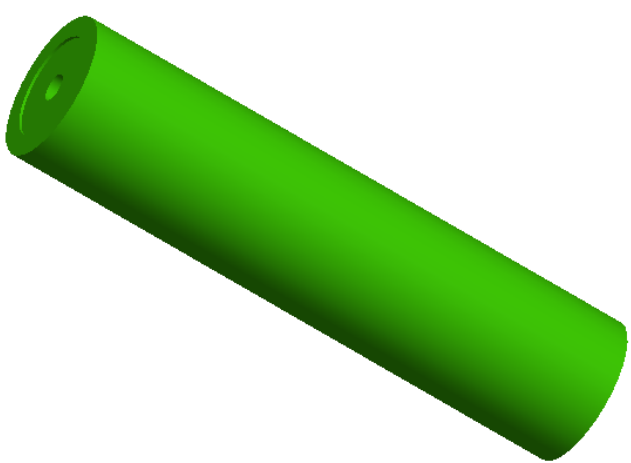

Fig.10 Punch in 3D
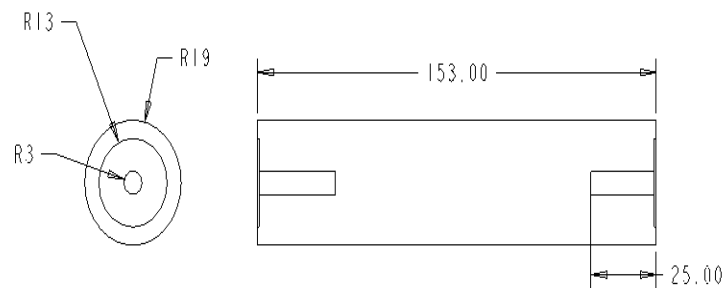

Fig.11 Punch in 2D

\section{B. DRAWING OF DIE}

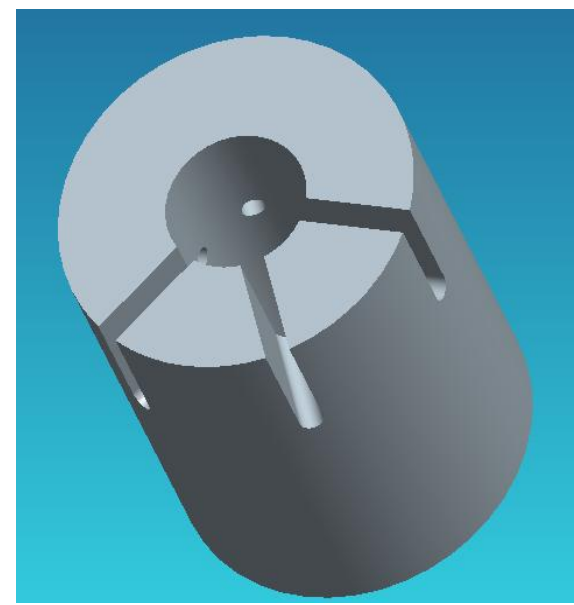

Fig.12 Die in 3D 


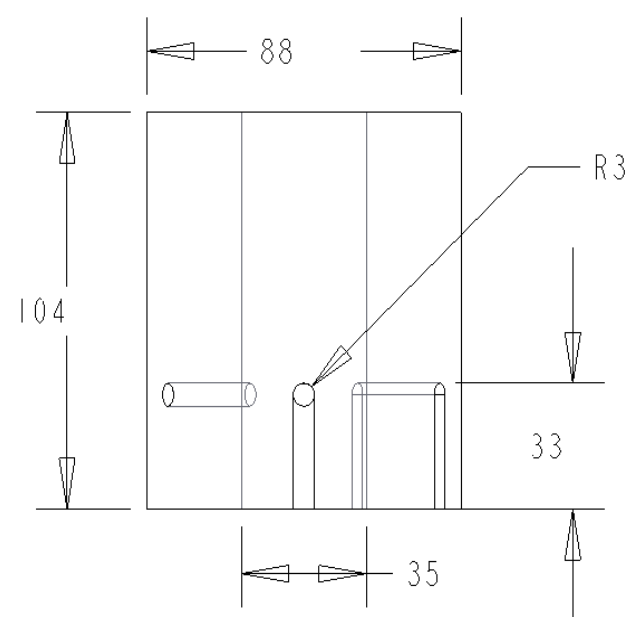

Fig.13 Die in 2D

\section{PUNCH HOLDER}

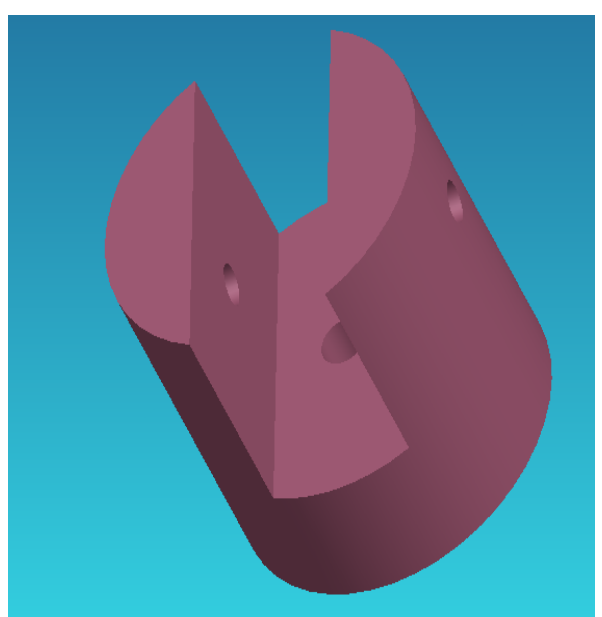

Fig.14 Punch Holder in 3D
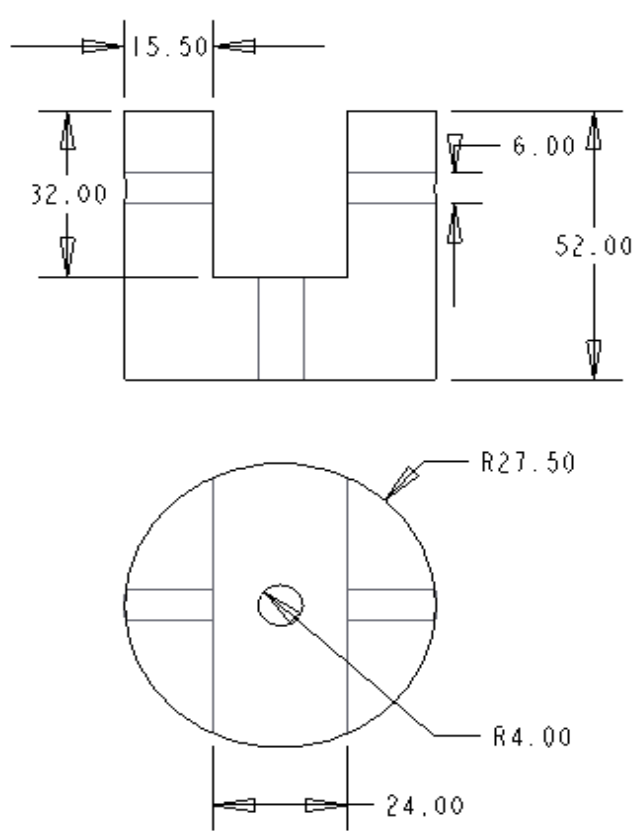

Fig.15 Punch Holder in 2D

\section{COST ESTIMATION}

The total raw material cost as per the individual materials and their corresponding rates per $\mathrm{kg}$ is as follows:

TABLE VIII Raw material cost

\begin{tabular}{|l|l|}
\hline Operation & Cost (Rs) \\
\hline Sawing & 50 \\
\hline Welding & 500 \\
\hline Bench Work & 100 \\
\hline Total & 650 \\
\hline
\end{tabular}

TABLE IX Machining and process costs

\begin{tabular}{|l|c|c|c|}
\hline Operation & $\begin{array}{c}\text { Rate Rs } \\
\text { /Hr }\end{array}$ & $\begin{array}{c}\text { Total time } \\
\text { Hrs }\end{array}$ & $\begin{array}{c}\text { Total cost } \\
\text { Rs/- }\end{array}$ \\
\hline Lathe & 200 & 2.5 & 500 \\
\hline $\begin{array}{l}\text { Milling / } \\
\text { Drilling }\end{array}$ & 600 & 4.6 & 2800 \\
\hline Tapping & $\begin{array}{c}\text { Rs100 /- } \\
\text { per hole }\end{array}$ & 6 holes & 600 \\
\hline Hardening & - & - & 300 \\
\hline Grinding & - & - & 4500 \\
\hline \multicolumn{3}{|c|}{ Total } & 8700 \\
\hline
\end{tabular}

TABLE X Miscellaneous cost

\begin{tabular}{|c|c|c|c|}
\hline Material & $\begin{array}{c}\text { Weight in } \\
\mathbf{~ k g}\end{array}$ & $\begin{array}{c}\text { Rate } \\
\text { (Rs/kg) }\end{array}$ & $\begin{array}{c}\text { Total cost } \\
\text { (Rs/-) }\end{array}$ \\
\hline HCHCr & .7 .28 & .300 & .2184 \\
\hline MS & 12 & 100 & 1200 \\
\hline \multicolumn{3}{|c|}{ Total } & 3384 \\
\hline
\end{tabular}

TABLE XI Cost of purchased parts

\begin{tabular}{|c|c|c|c|}
\hline $\begin{array}{c}\text { Sr. } \\
\text { no }\end{array}$ & Part name & Quantity & $\begin{array}{c}\text { Material } \\
\text { Cost }\end{array}$ \\
\hline 1 & Pneumatic cylinder & 1 & 5075 \\
\hline 2 & Nut -Bolt & 6 & 60 \\
\hline 3 & Pneumatic connector & 5 & 300 \\
\hline 4 & Pneumatic hoses & 2.5 & 150 \\
\hline 5 & Foot operated valve & - & 1500 \\
\hline 6 & Fork & & 600 \\
\hline 7 & Male clevis & - & 500 \\
\hline 8 & Female clevis & - & 500 \\
\hline & & & \\
\hline Total & 8685 & \multicolumn{2}{|l}{} \\
\cline { 2 - 3 }
\end{tabular}

Total Cost $=$ Raw Material Cost $+\quad$ Machine Cost + Miscellaneous Cost + Cost of Purchased Parts $=3384+8700+650+8685$

Hence, the total cost of machine $=$ Rs. $21,419 /-$

\section{FUTURE SCOPE}

- Automation can be made for operations like bar feeding \& cutting. 
- We can cut bar of $8 \mathrm{~mm}$ also by using hydraulic force at input.

\section{CONCLUSION}

The bar cutting machine is used to cut mild steel bar by using shearing operation. Shearing operation between punch and die, the pressure exerted by punch causes the metal to be deformed plastically in the die. As the clearance between punch and die is very small, the plastic deformation takes place in localized area and the metal adjacent to the cutting edge of the punch and the die becomes highly stressed. When the stress reaches beyond the ultimate strength of the material, the bar will be cut. The construction is very simple. Air is used as working fluid which is free amount. It is easy to handle. Skilled labour is not required. Less maintenance is required.

\section{REFERENCES}

[1] V.B. Bhandari; Design of Machine Elements; Tata McGraw hill Publication

[2] R.S. Khurmi; Machine Design; S. Chand and Company

[3] R.S. Khurmi; Strength of Material; S. Chand and Company

[4] Design Data Book; PSG College of Tech. Coimbatore;

[5] Hajra Chaudhari \& Nirjhar Roy; Workshop Technology Vol-2; Media Promoters \& Publishers PVT.LTD.

[6] D. J. Dunn; Applications of pneumatic and Hydraulic Cylinders

[7] Dalloz, J. Besson , A.-F. Gourgues-Lorenzon , T. Sturel , A. Pineau (1998); Effect of shear cutting on mild steel; Arcelor-Mittal Research, Voie Romaine, 57283 Maizières-lès-Metz Cedex, France

[8] Slavko Dolinšek, Borivoj Šuštarš(2001); Mechanisms of cutting tools in high-speed cutting processes;Institute of Metals and Technology, Ljubljana, Slovenia

[9] Smith \& Associates; Good Cutting Punch and Die Maintenance D30.doc REV March 18, 2004;530 Hollywood Drive, Monroe, Michigan 48162-2943 (C) 1993, 2001 